\title{
DENTAL CARIES EXPERIENCE IN 12-YEAR-OLD SCHOOLCHILDREN IN SOUTHEASTERN BRAZIL
}

\author{
Silvia CYPRIANO ${ }^{1}$, Rosana H. S. HOFFMANN ${ }^{2}$, Maria da Luz R. de SOUSA ${ }^{3}$, Ronaldo S. WADA ${ }^{4}$
}

1- DDS, PhD, Professor, Department of Preventive Dentistry, Pontifical Catholic University, Campinas, SP, Brazil.

2- DDS, MSc, PhD Student, Department of Cariology, Dental School of Piracicaba, State University of Campinas, Piracicaba, SP, Brazil.

3- DDS, MSc, PhD, Chair Professor, Department of Community and Preventive Dentistry, Public Health Area, Dental School of Piracicaba, State University of Campinas, Piracicaba, SP, Brazil.

4- DDS, MSc, PhD, Professor, Department of Social Dentistry, Biostatics Area, Dental School of Piracicaba, State University of Campinas, Piracicaba, SP, Brazil.

Corresponding address: Profa. Dra. Maria da Luz R. de Sousa - Departamento de Odontologia Social - Avenida Limeira, 901, 13414-018 Piracicaba, SP, Brasil - Phone: +55-19-2106-5364. Fax: +55-19-2106-5250 - e-mail: luzsousa@fop.unicamp.br

Received: September 17, 2007 - Modification: January 24, 2008 - Accepted: March 3, 2008

\begin{abstract}
The

aim of this study was to evaluate the prevalence of caries-free children using DMFT and significant caries (SiC) indexes in different caries prevalence groups in cities of the region of Campinas, São Paulo State, Brazil. The methodology proposed by the World Health Organization (1997) was used for caries diagnosis in 2,378 individuals. According to the DMFT index obtained in each evaluated city, 3 prevalence groups with representative samples were formed, being classified as low, moderate and high. $\mathrm{SiC}$ index was used to classify the one third of the population with the highest caries prevalence. In the low prevalence group, $32.4 \%$ of the children were caries free (DMFT=0), with mean DMFT of 2.29 and $\mathrm{SiC}$ index of 4.93 . In the moderate prevalence group, $21.8 \%$ of the children were caries free, with mean DMFT of 3.36 and $\mathrm{SiC}$ of 6.74 . Only $6.9 \%$ of the children in the high prevalence group were caries free and the mean DMFT was $5.54(\mathrm{SiC}=9.62)$. There was a great heterogeneity in dental caries distribution within the studied population, as well as a high caries prevalence considering the 3 classifications. Other indexes besides DMFT could be used to improve oral health assessment during establishment of the treatment plan and intervention.
\end{abstract}

Key Words: Epidemiology. Oral health. Dental caries. DMF index.

\section{INTRODUCTION}

Significant gains in oral health levels have been observed over the last few years in countries like Germany ${ }^{16}$, England, USA, Scandinavia, Scotland ${ }^{18}$, Norway ${ }^{4}$ and Australia ${ }^{11}$. Several researchers believe that the use of different fluoridereleasing vehicles has significantly contributed to such dental caries decline $e^{4,5,14,18}$. There is a consensus among experts who consider the addition of fluoride to dentifrices as the main strategy to reduce dental caries prevalence ${ }^{7,13}$. However, several population groups still have a high caries experience and a great need for dental care $3,6,10,11,19,20,21,23$. Finding instruments and effective strategies to minimize the inequalities in oral health levels remains a major challenge.

Bratthall $^{8}$ (2000) developed the significant caries (SiC) index to select individuals with the highest caries scores. The validity of this tool has been confirmed by Marthaler ${ }^{14}$ (2004), who reported that dental caries assessment can be done regardless of the socioeconomic level.

Several Brazilian studies have shown a decrease in the prevalence and severity of dental caries, mainly among schoolchildren. Bönecker and Cleaton-Jones ${ }^{9}$ (2003) detected this trend towards a decrease in dental caries among children from Latin America and the Caribbean. National epidemiological surveys conducted by the Brazilian Ministry of Health in 1996 and 2003 showed a DMFT reduction of $9.15 \%$ (3.06 to 2.78 ) in 12-year-olds. Epidemiological surveys are needed to verify whether this trend in DMFT polarization does exist. Thus, the aim of the present study was to evaluate the percentage of caries-free children, as well as the DMFT and $\mathrm{SiC}$ indexes focusing on different caries prevalence groups in 12-year-olds living in the southeastern Brazil.

\section{MATERIALAND METHODS}

The present study was independently reviewed and approved by the Research Ethics Committee of the Dental School of Piracicaba, State University of Campinas, Brazil.

Oral health epidemiological surveys involving 29 cities located in the region of Campinas (São Paulo State, Brazil) 
were carried out between 1998 and 2001. In order to reach this number, all cities from the region of Campinas were first pre-stratified according to their size [large (more than 50,000 inhabitants), medium-sized (10,000-50,000 inhabitants) and small (fewer than 10,000 inhabitants)], and dental caries prevalence (cities with moderate and high caries prevalence). The city sample size was defined according to the specifications of the World Health Organization ${ }^{24}$ (1997) for areas with moderate and high caries prevalence. Public and private schools were randomly selected from the official information records supplied by each city's Education Department. The 12-year-olds enrolled in this survey studied at these schools and were selected by systematic sample without reposition. Only children whose parents/guardians signed an informed consent form and were present on the day of the survey were included. Schoolchildren having 5 or more orthodontic brackets were excluded.

The authors participated in all study phases, including calibration, data collection and analysis of the results. Prior to the survey, calibration exercises comprising practical and theoretical activities were carried out by dentists who were adequately calibrated by S.C and M.L.R.S. at intermittent periods totaling $24 \mathrm{~h}$. Inter-examiner reliability was assessed and a percentage agreement of $85 \%$ was reached. Because of the large number of cities, the examinations were carried out by groups varying from 7 to 25 examiners, regardless of the cities assessed in each year during the study period. During data collection, duplicate examinations of approximately $10 \%$ of the children were performed to assess intra-examiner variability. WHO' ${ }^{24}$ international standards were used to perform the epidemiological survey. Children, lying on a school desk, were examined either in a classroom under artificial light or outdoors under natural light. Adental mirror and a CPI probe were used in each examination. Results were recorded on a form developed by the Public Health School, University of São Paulo, Brazil.

Twenty-nine out of 42 cities were assessed. Areas with very low caries prevalence and/or considerably insufficient number of individuals were excluded. Digitized epidemiological data were obtained from each city. Typing was reviewed and DMFT values were checked. Cities were classified according to a scale as an indicator of oral health: DMFT 0 to 1.1 (very low prevalence); DMFT 1.2 to 2.6 (low prevalence); DMFT 2.7 to 4.4 (moderate prevalence); DMFT 4.5 to 6.5 (high prevalence) and DMFT $>6.6$ (very high prevalence). Caries prevalence was established and the number of children was determined to verify if it was sufficient for statistical analysis. The variability (SD) of DMFT mean values was used to verify whether samples were representative of each level of prevalence, considering an error of $5 \%$ and a confidence interval of $95 \%$.

Percentage of caries-free scholars $(\mathrm{DMFT}=0)$ and DMFT and $\mathrm{SiC}$ indexes ${ }^{8}$ were used to describe dental caries distribution in each prevalence group and to evaluate caries distribution among the individuals. $\mathrm{SiC}$ index calculations were used to classify the children according to their DMFT, to select the one third of the population with the highest caries scores, and to calculate the mean DMFT for the

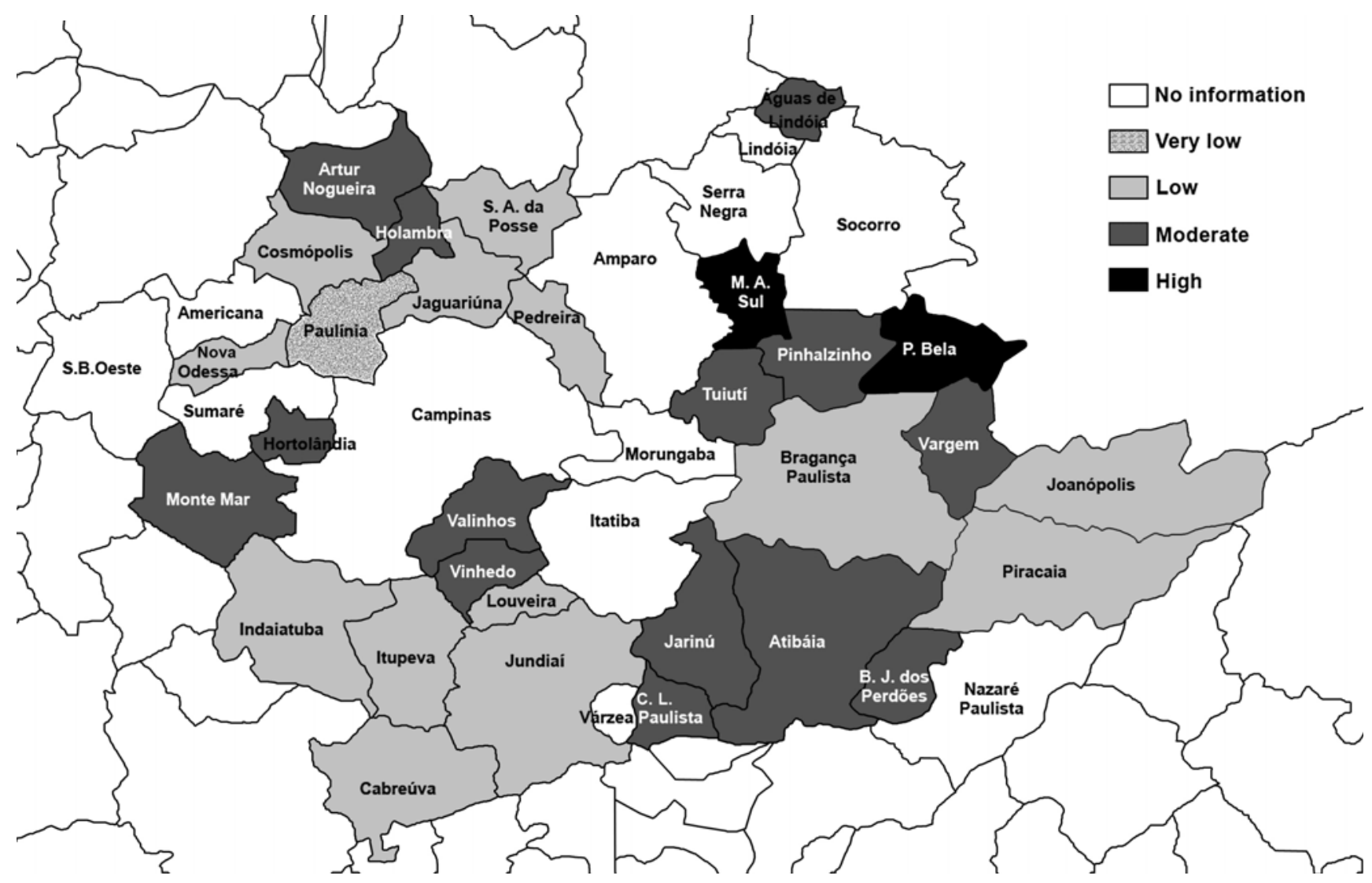

FIGURE 1- Dental caries prevalence according to the prevalence scale in cities from the region of Campinas, São Paulo State, Brazil (1998 to 2001) 
subgroups. SiC mean values were obtained according to the subgroup (one third of the population) with the highest dental caries prevalence, and the other subgroups (two thirds of the population) with lower dental caries prevalence.

Excel $^{\circledR}$ software ${ }^{25}$ (www.whocollab.od.mah.se/expl/ siccalculation.xls) was used to calculate $\mathrm{SiC}$ index. EPI-Info software was used to calculate DMFT index and the percentage of caries-free individuals. The chi-square test was used to verify different proportions among caries-free schoolchildren. Differences among DMFT and SiC index values, concerning the groups with low, moderate and high caries prevalence, were analyzed by the Mann-Whitney Utest. Nonparametric tests were used for the variables with a non-normal distribution. A statistical significance level of $5 \%$ was adopted.

\section{RESULTS}

The percentage of inter-examiner agreement ranged from 92.5 to $98.5 \%$. These values are admissible according to the WHO' ${ }^{24}$ criteria. Intra-examiner agreement ranged from 89 to $99.8 \%$. The response rate was $84.1 \%$, as some subjects were absent on the day of the dental examination.

Examinations were carried out in 2,378 12-year-old children. Sample distribution concerning gender was equitable in all caries prevalence groups: 1,135 boys (47.7\%) and 1,243 girls (52.3\%). Most children examined were enrolled in state schools $(93.9 \%)$ and lived in urban areas $(89.8 \%)$. Figure 1 shows the geographic variance of caries experience in the assessed region, according to the prevalence scale. DMFT index ranged from 1.0 to 6.2 , revealing large heterogeneity of disease distribution in the areas.

Thirteen cities were classified as low prevalence, totaling 1,141 epidemiological exams (Table 1). The DMFT ranged

TABLE 1- Mean values for the DMFT, SiC indexes and caries-free percentage for 12-year-old children in the cities evaluated in the region of Campinas, São Paulo State, 1998 to 2001

\begin{tabular}{|c|c|c|c|c|}
\hline Cities & $\begin{array}{l}\text { Sample } \\
\qquad \mathbf{N}\end{array}$ & $\begin{array}{l}\text { DMFT } \\
\text { means }\end{array}$ & $\begin{array}{l}\text { SiC index } \\
\text { means }\end{array}$ & $\begin{array}{c}\text { Caries free children (DMFT=0) } \\
\%\end{array}$ \\
\hline \multicolumn{5}{|l|}{ Low prevalence group } \\
\hline Pedreira & 54 & 1.76 & 4.00 & 42.6 \\
\hline Indaiatuba & 88 & 1.84 & 5.00 & 43.2 \\
\hline Jaguariúna & 85 & 1.88 & 4.35 & 36.5 \\
\hline Cabreúva & 64 & 2.17 & 5.00 & 25.0 \\
\hline Jundiaí & 99 & 2.30 & 5.41 & 38.4 \\
\hline Itupeva & 104 & 2.33 & 4.86 & 30.8 \\
\hline Cosmópolis & 85 & 2.34 & 4.81 & 32.9 \\
\hline Nova Odessa & 102 & 2.41 & 4.40 & 33.3 \\
\hline Santo Antônio da Posse & 86 & 2.42 & 4.74 & 25.6 \\
\hline Louveira & 87 & 2.43 & 4.87 & 27.6 \\
\hline Bragança Paulista & 84 & 2.51 & 6.59 & 36.9 \\
\hline Joanópolis & 130 & 2.51 & 5.67 & 27.9 \\
\hline Piracaia & 73 & 2.64 & 4.50 & 21.9 \\
\hline \multicolumn{5}{|c|}{ Moderate prevalence group } \\
\hline Monte Mor & 87 & 2.71 & 6.58 & 27.6 \\
\hline Jarinu & 90 & 2.71 & 6.38 & 25.6 \\
\hline Vinhedo & 81 & 2.83 & 7.21 & 38.3 \\
\hline Bom Jesus dos Perdões & 61 & 2.98 & 5.96 & 21.3 \\
\hline Holambra & 31 & 3.13 & 8.13 & 35.5 \\
\hline Atibaia & 59 & 3.19 & 7.87 & 30.5 \\
\hline Pinhalzinho & 68 & 3.28 & 5.34 & 20.6 \\
\hline Valinhos & 72 & 3.50 & 5.83 & 16.7 \\
\hline Arthur Nogueira & 100 & 3.59 & 7.03 & 22.0 \\
\hline Campo Limpo Paulista & 66 & 3.60 & 7.18 & 16.7 \\
\hline Águas de Lindóia & 76 & 3.62 & 7.48 & 18.4 \\
\hline Tuiuti & 62 & 3.70 & 6.79 & 12.9 \\
\hline Vargem & 104 & 3.90 & 6.70 & 13.5 \\
\hline Hortolândia & 92 & 4.00 & 7.69 & 15.2 \\
\hline \multicolumn{5}{|l|}{ High prevalence group } \\
\hline Pedra Bela & 123 & 5.20 & 9.64 & 3.1 \\
\hline Monte Alegre do Sul & 65 & 6.20 & 9.61 & 8.9 \\
\hline
\end{tabular}


from 1.76 to $2.64, \mathrm{SiC}$ index ranged from 4.00 to 6.59 and caries-free percentage ranged from 43.2 to 21.9 , showing heterogeneous levels of dental caries. Moderate prevalence was found in 14 cities $(n=1,018)$, with values ranging from 2.71 to 4.00 for DMFT, 5.34 to 8.13 for $\mathrm{SiC}$ index, and 35.5 to 12.9 for caries free percentage. Only 2 cities $(n=188)$ were classified as high caries prevalence. Very high prevalence was not found (Table 1). Considering the total sample, the DMFT was 3.02, the $\mathrm{SiC}$ index was 6.22 and the caries-free percentage was $25.7 \%$ (Table 1 ).

Figure 2 shows the dental caries experience and distribution for the low, moderate and high prevalence groups. Mean values for decayed teeth ranged from 2.29 to
5.54, concerning the three prevalence groups (low, moderate and high). Statistically significant differences $(\mathrm{p}<0.001)$ were observed among the prevalence groups.

Considering the WHO goals for the year 2000 (DMFT=3), the mean values for the cities with low prevalence in the present study were lower than such value. Considering all cities, $58.6 \%$ presented DMFT mean values $<3$. Figure 3 illustrates the $\mathrm{SiC}$ index values recorded in the different caries prevalence groups. This index, representing the one-third of the population that was the most affected by caries disease, ranged from 4.93 to 9.62 . There was statistically significant difference among the groups $(\mathrm{p}<0.001)$. The other two-thirds of the population that presented the lowest DMFT

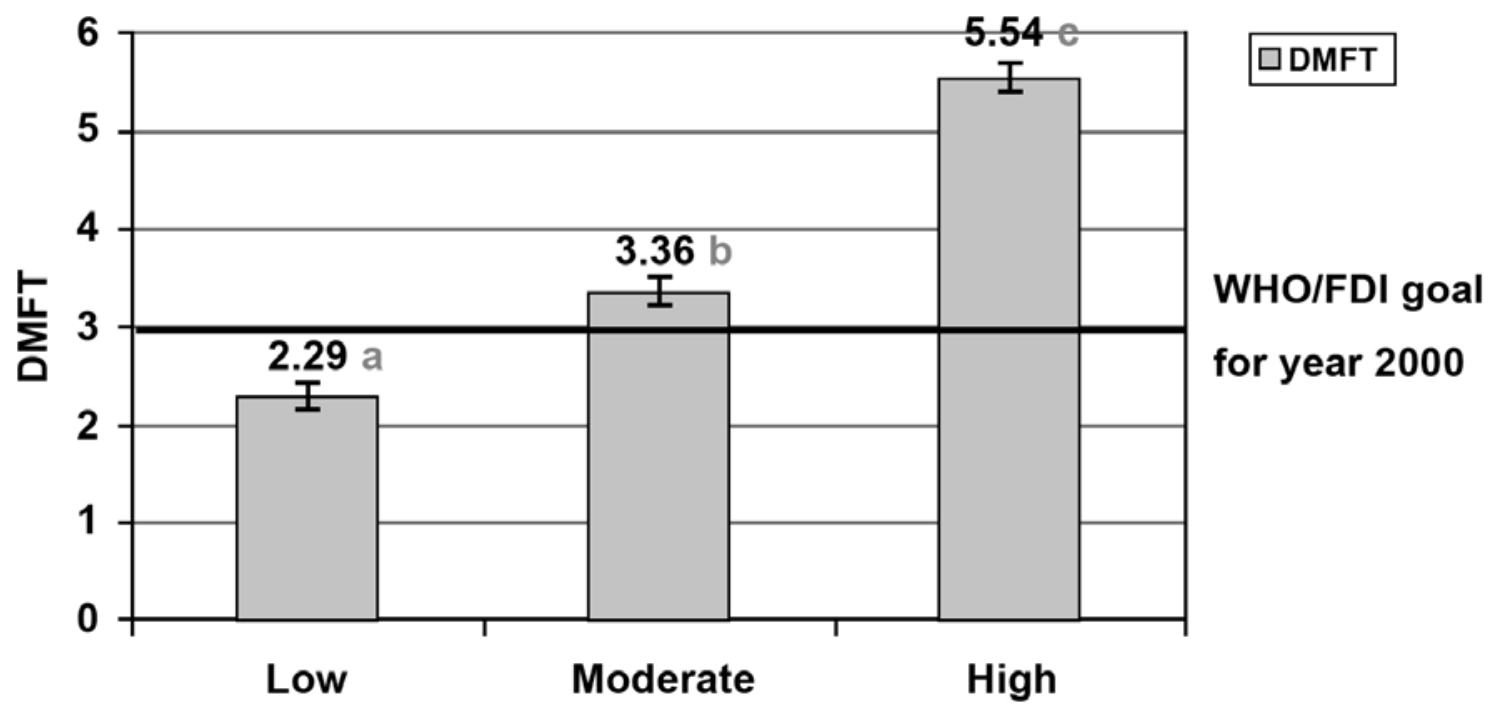

FIGURE 2- DMFT index among 12 year-old children (95\% confidence interval), according to dental caries prevalence in cities from the region of Campinas, São Paulo State, Brazil (1998 to 2001). Different letters indicate statistically significant difference at $5 \%$
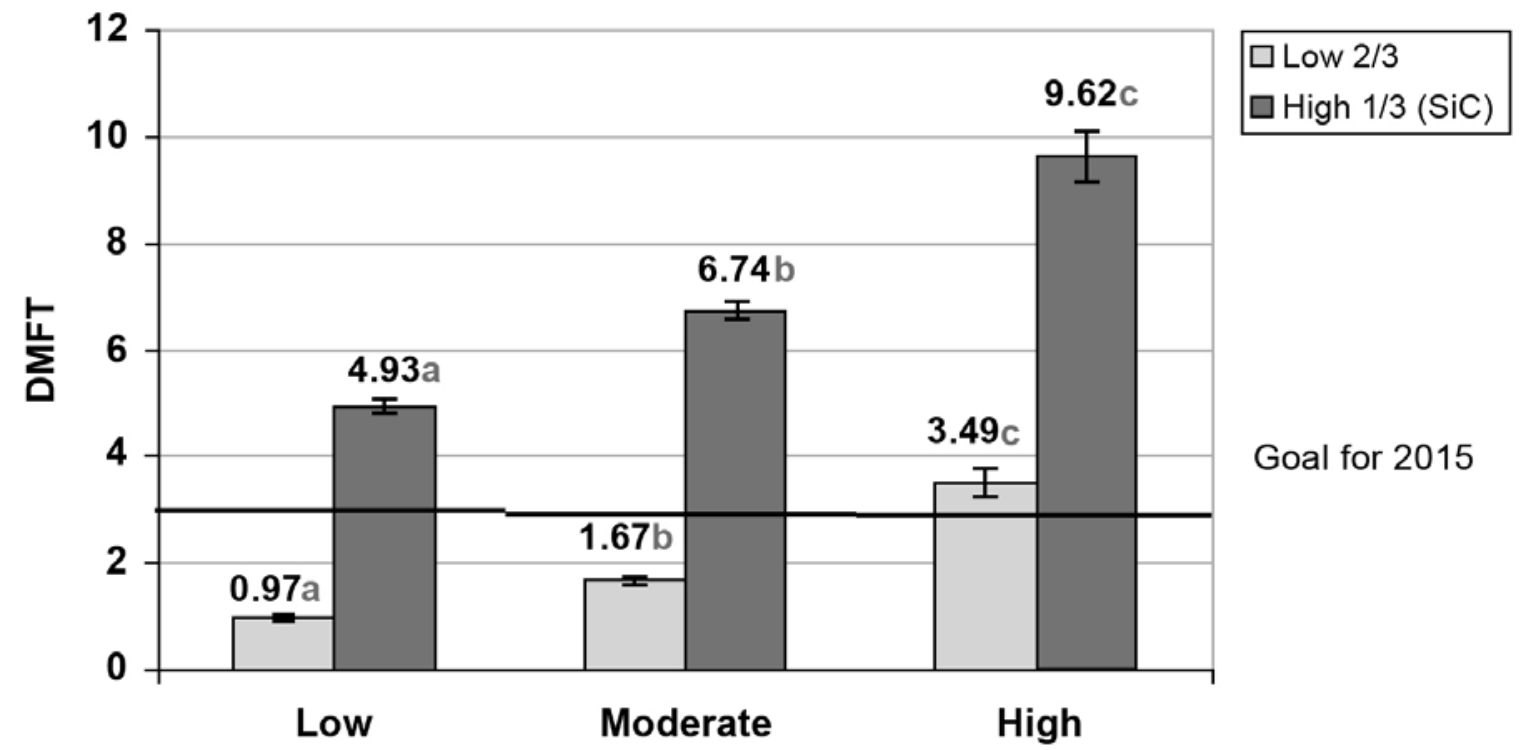

Goal for 2015

FIGURE 3- Mean caries levels for schoolchildren with the highest dental caries prevalence (one-third of the surveyed population; SiC index) and for schoolchildren with the lowest caries scores (two-thirds of the surveyed population) in cities from the region of Campinas, São Paulo State, Brazil (1998 to 2001). Different letters indicate statistically significant difference at $5 \%$ 


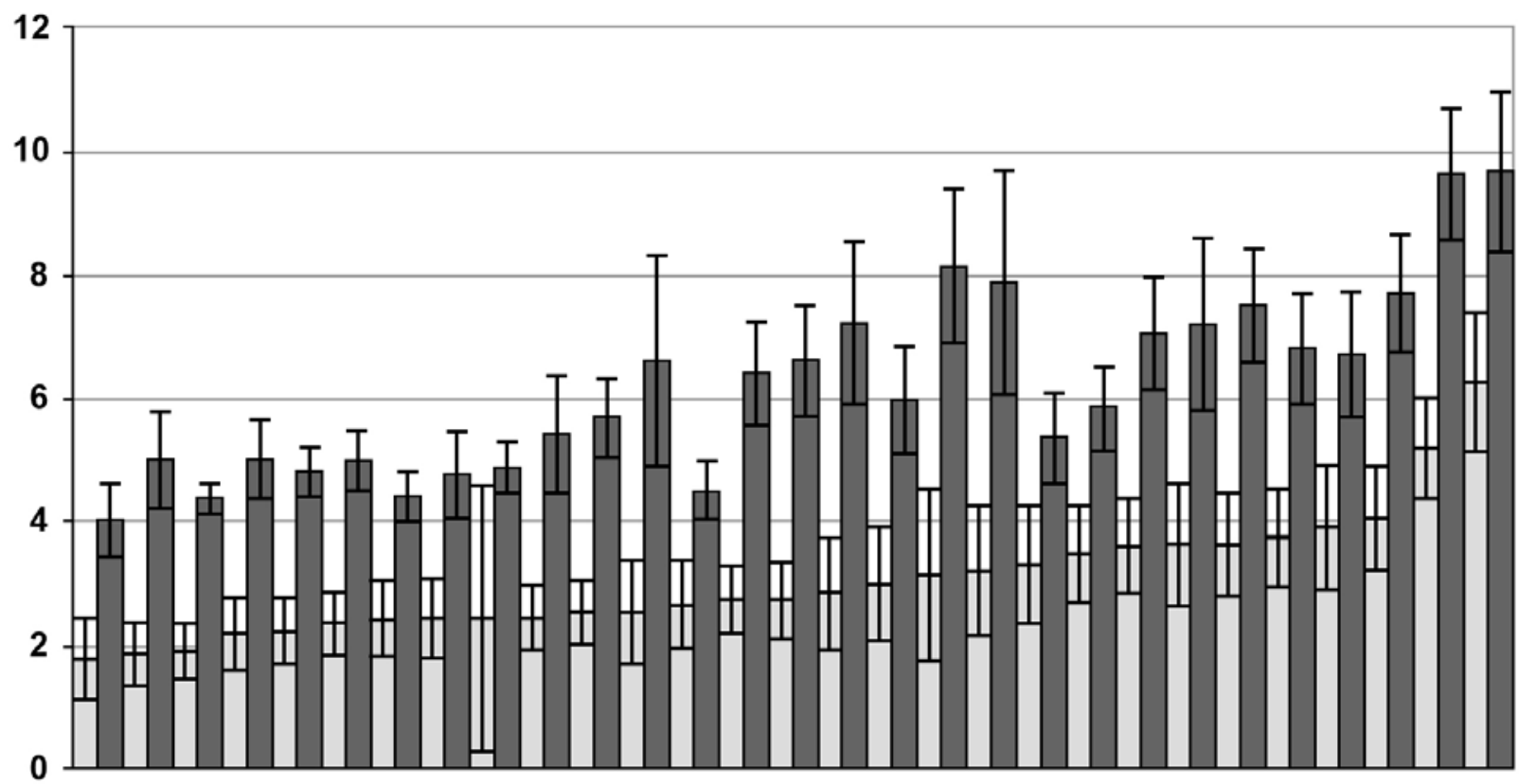

\section{DMFT}

SiC Index

FIGURE 4- DMFT and $\mathrm{SiC}$ index with $95 \%$ confidence interval in cities from the region of Campinas, São Paulo State, Brazil (1998 to 2001)

scores, also showed statistically significant differences among the groups $(\mathrm{p}<0.001)$, which clearly demonstrates the inequalities in the oral health pattern, when compared to the remaining population (two thirds) least affected by dental caries.

Figure 4 shows the distribution of the DMFT and $\mathrm{SiC}$ index in the cities evaluated in this study.

\section{DISCUSSION}

Campinas region showed good oral health levels in the surveyed 12-year-old-children population. Caries prevalence was low in $44.8 \%$ of the evaluated cities. High caries prevalence was found in only $6.9 \%$ of the cities.

Conversely, Baldani, et al. ${ }^{1}$ (2002) reported a low caries prevalence among 12-year-old schoolchildren in $7.3 \%$ of the cities the state of Paraná, Brazil, while a high prevalence was found in most cities (means DMFT=5.38). Likewise, Peres, et al. ${ }^{17}$ (1997) reported a low caries prevalence among 12-year-olds in only few cities of the state of São Paulo (4.0\%), between 1990 and 1995 , while $80.0 \%$ of the cities presented a high or very high caries prevalence.

In the present study, most cities in the region of Campinas achieved the WHO goals for the year 2000 (DMFT=3) (FDI, $1982)^{12}$. However, as shown in Table 1, high $\mathrm{SiC}$ index values and low percentage of caries-free children were found for some cities where caries prevalence was classified as low. These findings are most likely related to the socioeconomic level of the evaluated cities. Other important factors, such as local service organization, access to fluoridated water and preventive procedures, investment in public health and health promotion measures, might also contribute to these findings.

Baldani, et al. ${ }^{1}$ (2002) reported that social, ethnical and cultural differences might result in distinct health profiles. Bratthall $^{8}$ (2000) stated that less privileged population subgroups in some areas are 5 to 37 times more likely to develop caries. This denotes a skewed distribution of dental caries. While some children have high or very high DMFT values, others are caries free or show low DMFT values.

In the present study, $\mathrm{SiC}$ index was used to identify the high caries experience group and plan strategies to decrease the inequalities in oral health patterns. Therefore, in addition to the DMFT index, other approaches for caries evaluation should be considered. Marthaler ${ }^{14}$ (2004), analyzing the changes in dental caries, mentioned an advantage of the $\mathrm{SiC}$ index that allows comparing different real situations, which is the fact that this index does not require any socioeconomic level assessment, thereby avoiding different ways of interpretation.

In countries like Germany ${ }^{16}$, United Kingdom ${ }^{19}$, Switzerland, Mexico and Uruguay ${ }^{25}$, when the mean DMFT values ranged from 1.2 to 2.5 , denoting low caries prevalence, the $\mathrm{SiC}$ index ranged from 3.2 to 5.3. DMFT and $\mathrm{SiC}$ mean values obtained in the present study were similar to those recorded in countries like Mexico and Uruguay ${ }^{25}$. Lower values for such indexes were observed in the USA ${ }^{8}$ and Switzerland ${ }^{25} 10$ years ago, showing better oral health patterns. When DMFT mean values ranged from 2.8 to 4.4 (moderate caries prevalence) in countries like Nicaragua, Portugal and $\mathrm{Mexico}^{25}$, the $\mathrm{SiC}$ index ranged from 5.7 to 7.5. 
However, lower values than the ones (DMFT 5.5; SiC 9.6) found in the present study were observed in countries like Portugal, Bolivia (DMFT 4.7; SiC 8.8) and Greece (DMFT 4.5 and $\mathrm{SiC} 8.1)^{25}$.

In the present study, considering all prevalence patterns (low, moderate, and high), DMFT and SiC means values were observed to increase simultaneously. However, the ratio of caries-free individuals was found to range from 21.9 to $43.2 \%, 12.9$ to $38.3 \%$ and 3.1 to $8.9 \%$ for the low, moderate, and high prevalence groups, respectively.

The inequalities in oral health are remarkable and easily noted among caries-free children. Children residing in areas with moderate caries prevalence were 3.8 times more likely to be caries-free when compared to children living in high caries prevalence areas. The chances are even higher when children living in low prevalence areas are compared to those living in high prevalence areas (6.5 times).

Vehkalahti, et al. ${ }^{22}$ (1997) reported that even when positive changes in oral health occur, there is a group within the population with greater need for oral heath care, suggesting that a preventive strategy, including early identification of high-risk patients and individualized treatment, should be considered.

Analyzing the $\mathrm{SiC}$ index mean values among the different caries prevalence groups, there is one that can easily be seen to have the worst health levels (Figure 3). Figure 3 shows mean caries levels for one-third of the children with the highest caries scores ( $\mathrm{SiC}$ index) and for two-thirds of the children with the lowest caries scores. Based on the results of the present study and on the WHO's guidelines for dental caries in 12-year-olds in the years $2000^{12}$ and $2015^{8}$, specific strategies should be developed for the different situations concerning oral health status. Burt ${ }^{10}$ (1998) evaluated the oral health conditions in Scandinavian countries and proposed preventive approaches to reduce dental caries levels in the population as a whole, in areas with the highest caries prevalence, and in high-caries-risk individuals.

In the region studied in the present study, a first step would be to meet the DMFT $=3$ goal in all areas by implementing preventive and educational oral health measures, aiming at the population as a whole. Secondly, there is a need to identify areas with high caries levels, even if the DMFT $=3$ goal had already been achieved, and develop oral health strategies for the groups with the highest caries prevalence. Finally, individualized approaches should be applied, promoting reasonable, effective and lasting health actions. Strategies directed to the whole population should always be considered irrespective of health-disease levels ${ }^{2}$, not only to maintain or decrease caries levels, but also to increase the proportion of caries-free individuals, providing broad benefits to all people.

\section{CONCLUSIONS}

The data referring to the percentage of caries-free children as well as the DMFT and SiC indexes revealed significant differences among the caries prevalence groups. However, the $\mathrm{SiC}$ index was efficient in measuring high caries experience in more vulnerable populations. Also, it enabled rapid and simple comparisons among different areas. The $\mathrm{SiC}$ index and the percentage of caries-free children should be considered for oral health assessments, irrespective of caries prevalence. In addition, it is important to evaluate caries experience not only in large territorial areas, such as states, countries and continents, but also at local and regional levels, promoting adequate oral health based on the community needs.

\section{REFERENCES}

1- Baldani MH, Narvai PC, Antunes JLF. Dental caries and socioeconomic conditions in the State of Paraná, Brazil, 1996. Cad Saude Publica. 2002;18:755-63.

2- Batchelor P, Sheiham A. The limitations of a "high-risk" approach for the prevention of dental caries. Community Dent Oral Epidemiol. 1999;30:302-12.

3- Beltrán-Aguilar ED, Estupiñán-Day S, Báez R. Analysis of prevalence and trends of dental caries in the Americas between the 1970s and 1990s. Int Dent J. 1999;49:322-9.

4- Birkeland JM, Haugejorden O, Fehr FR. Analyses of the caries decline and incidence among Norwegian adolescents 1985-2000. Acta Odontol Scand. 2002;60:281-9.

5- Birkeland JM, Haugejorden O, Fehr FR. Some factors associated with the caries decline among Norwegian children and adolescents: age-specific and cohort analyses. Caries Res. 2000;34:109-16.

6- Bjarnason S, Finnbogason SY, Holbrook P, Khöler B. Caries experience in Icelandic 12-year-old urban children between 1984 and 1991. Community Dent Oral Epidemiol. 1993;21:194-7.

7- Bratthall D, Petersson HG, Sundberg H. Reasons for the caries decline: what do the experts believe? Eur J Oral Sci. 1996;104:41622 .

8- Bratthall D. Introducing the Significant Caries Index together with a proposal for a new global oral health goal for 12-years-olds. Int Dent J. 2000;50:378-84

9- Bönecker M, Cleaton-Jones P. Trends in dental caries in Latin American and Caribbean 5-6 and 11-13-year-old children: a systematic review. Community Dent Oral Epidemiol. 2003;31:152-7.

10- Burt BA. Prevention policies in the light of the changed distribution of dental caries. Acta Odontol Scand. 1998;56:179-86.

11- Davies MJ, Spencer AJ, Slade GD. Trends in dental caries experience of school children in Australia - 1977 to 1993. Aust Dent J. 1997;42:389-94.

12- Federation Dentaire International. Global goals for oral health in the year 2000. Int Dent J. 1982;32:74-7.

13- Krasse B. The caries decline: is the effect of fluoride toothpaste overrated? Eur J Oral Sci. 1996;104:426-9.

14- Marthaler TM. Changes in dental caries 1953-2003. Caries Res. 2004;38:173-81 
15- Nordblad A. Changes in epidemiologic pattern of dental caries in cohorts of schoolchildren in Espoo, Finland, during a 3-year period. Community Dent Oral Epidemiol. 1986;14:126-7.

16- Pieper K, Schulte AG. The decline in dental caries among 12year-old children in Germany between 1994 and 2000. Community Dent Health. 2004;21:199-206.

17- Peres MA, Narvai PC, Calvo MC. Prevalence of dental caries in a 12-year-old population in localities in Southeastern Brazil, during the period 1990-1995. Rev Saude Publica. 1997;31:594-600.

18- Petersson HG, Bratthall D. The caries decline: a review of reviews. Eur J Oral Sci. 1996;104:436-43.

19- Pitts NB, Evans DJ, Nugent ZJ, Pine CM. The dental caries experience of 12-year-old children in England and Wales. Surveys coordinated by the British Association for the Study of Community Dentistry in 2000/2001. Community Dent Health. 2002;19:46-53.

20- Traebert J, Suárez CS, Onofri DA, Marcenes W. Prevalence and severity of dental caries and treatment needs in small Brazilian counties. Cad Saude Publica. 2002;18:817-21.

21- Traebert JL, Peres MA, Galesso ER, Zabot NE, Marcenes W. Prevalence and severity of dental caries among schoolchildren aged six and twelve. Rev Saude Publica. 2001;35(3):283-8.

22- Vehkalahti M, Tarkkonen L, Varsio S, Heikkilä P. Decrease in and polarization of dental caries occurrence among children and young populations, 1976-1993. Caries Res. 1997;31:162-5.

23- Winter GB. Epidemiology of dental caries. Arch Oral Biol. 1990;35: Suppl:1S-7S

24- World Health Organization. Oral Health Surveys: basic methods. 4th ed. Geneva: WHO;1997.

25- World Health Organization. WHO oral health country/area profile program [homepage at internet]. Geneva: WHO; c2008 [cited 2008 Mar. 1]. Available from: http://www.whocollab.od.mah.se/sicdata.html. 